\title{
Phenotypic and functional properties of generated dendritic cells in lung cancer patients
}

\author{
Khranovska N. M., Skachkova O. V., Sovenko V. M., Sydor P. I., Inomistova M. V., Melnyk V. O. \\ National Cancer Institute, Kyiv, Ukraine \\ e-mail: nkhranovska@ukr.net
}

\section{ABSTRACT}

The application of dendritic cells (DC) as a «natural adjuvant» is widely used in various fields of cancer immunotherapy. This study is aimed to investigate phenotypic and functional characteristics of dendritic cells (DCs) generated from monocytes of peripheral blood of healthy volunteers and cancer patients.

MATERIAL AND METHODS. Dendritic cells were generated from the monocytes of 40 patients with non-small cell lung cancer (NSCLC) at IIBIIIA stages; the control group consisted of 10 healthy individuals. Monocytes were isolated from blood using Histopaque $(1.077 \mathrm{~g} / \mathrm{mL})$ and cultured in RPMI-1640 medium supplemented with $1 \%$ autologous plasma, $100 \mathrm{ng} / \mathrm{ml}$ of human GM-CSF and $20 \mathrm{ng} / \mathrm{mL}$ of IL-4 for 8 days. On the day 6 we used autologous lyophilized tumor cells as a source of tumor-associated antigens. One day later we added LPS (100 ng/mL) and $2 a b$-IFN (10,000 units/mL). Phenotypic and functional characteristics of DCs were identified by flow cytometry and real-time PCR.

RESULTS. We have found that in lung cancer patients generated DCs had moderate level of maturity and demonstrated more pronounced tolerogenic features in contrast to DCs of healthy volunteers: patients' DCs had higher mRNA expression levels of TGF- $\beta$ and IDO, and secreted lower amount of IL-12. Expression of CCR7 gene was particularly on the normal level in DCs of cancer patients, which indicates on saving of migratory properties of these cells. Expression of DCs' maturity marker CD83 increased after each subsequent vaccine administration while TGF- $\beta$, IL-10 mRNAs levels decreased to the end of vaccine therapy course decreased to the level observed in DCs of healthy volunteers.

CONCLUSION. Thus, the study of biological characteristics of DCs will help to improve and develop the most effective protocols for rational use of $D C$ vaccines. These data indicate the need for further optimization of technologies of DC generation in patients with lung cancer with emphasis on the stimulation of Th1-polarizing properties by increasing cytokine-secreting potential.

KEYWORDS: Iung cancer; immunotherapy; dendritic cells; TGF- $\beta$; IDO; IL-12

The most potent specialized antigen-presenting dendritic cells (DCs) have the ability to activate all the main effectors of antitumor immunity, such as CD8+ T-cells, T-helpers type 1 (Th1), natural killer cells (NK) and NK T-lymphocytes (NKT). Therefore, the use of DC as a «natural adjuvant» is widely used in various fields of immunotherapy, which component is cancer vaccinotherapy [1-3].

There are methods of DCs mobilization in cancer patients, comprising administering of growth factors and cytokines such as human granulocytemacrophage colony-stimulating factor (GM-CSF), FMS-like tyrosine kinase 3 ligand (FLT-3L), IL-12, IL-15, CD40L and TNF-a. After the DCs expansion in vivo, tumor antigens are administered into patients. At the same, endogenous DCs, which matured in cancer patients, are much less effective compared to control, obtained by culturing in vitro. In cancer immunotherapy the most widely used methods are growing of autologous DCs from precursors in sufficient quantities ex vivo, loading them with tumor-associated antigens (TAA) and induction of maturation followed by administration to the patient $[4,5]$. In this case, the immune response to the TAA starts in vitro, where we can accurately control the amount and functional status of DCs and ends in the body with the formation of specific cytotoxic T-lymphocytes (CTL). In addition, the plasticity of immature DCs functional activity allows, while varying conditions in vitro, to receive from them DCs with certain functional properties, including the ability to activate immunological reactions involving generally a cell part of the immune system. For this purpose, factors that promote maturation of cytokines are added to their combination, which is used for DCs cultivation [6-8]. 
The degree of maturity is considered an extremely important DCs characteristic in their use as a natural adjuvant in cancer vaccines [911]. This is because the use of DCs immature phenotype that have weak immunogenicity may lead to abortive proliferation and anergia of effector cells, induction of tolerance to tumor antigens as a result of activation of $\mathrm{CD}^{+}$and $\mathrm{CD} 8^{+}$regulatory $\mathrm{T}$-cells $\left(\mathrm{T}_{\text {reg }}\right)$, which secrete IL-10 and TGF- $\beta$.

However, any clear criteria for DCs standardization in creating cancer vaccines do not exist. They must meet a number of requirements that reflect their ability for antigen presentation and stimulation of T-cells: to be viable; to express high levels of markers of maturity of costimulatory and adhesion molecules; to secrete cytokines; to be able to activate CTLs and Th1-mediated immune response; as well as to express chemokine receptor CCR7, which is required for DCs migration to lymph nodes [12$14]$.

In cancer patients the functional activity of DCs derived from precursors is usually reduced, in particular, they are often resistant to many activating stimuli and remain immature. Anticancer chemotherapy and radiation therapy may also cause reduced effectiveness of formation and inhibition of DCs maturation, which can complicate and limit their application $[15,16]$. At the same, immature or partially mature DCs are also an optimal population for their use in anticancer immunotherapy [1719]. In particular, the first commercial vaccine Sipuleucel-T (Dendreon, USA) for the treatment of patients with hormone-refractory metastatic prostate cancer, approved by the FDA, contains a combination of immature and partially mature DCs loaded with peptides of prostate-specific antigen [20]. On the other hand, some authors note a significant drawback in mature DCs - a lack of a homing receptor CD62L for migration to the lymph nodes through the endothelium [21, 22].

At present, the optimal combination of DCs maturation inductors for their use in cancer immunotherapy is not described, and protocols to obtain functionally mature DCs are not standardized. Therefore, finding the most effective combinations of factors to produce functionally mature DCs, suitable for the use in cancer vaccines, remains an urgent problem. Much attention is paid to the use of toll-like receptors ligands (TLR), including lipopolysaccharide (LPS) or poly $(\mathrm{l}: \mathrm{C})[23,25]$. The use of TLR ligands in combination with cytokines provides DCs maturation, accompanied by phenotypic and functional changes, such as the acquisition of Th1 polarizing potential [24, 26].

Our previous studies have shown that the combination of two activating signals at the obtaining of monocyte-derived DCs - IFN- $a$ and LPS, has a significant modulating effect on their cytokine- and chemokine secretory activity, causing prevalence of proinflammatory potential and improving viability [27]. The obtained results justified the use of this obtaining DCs technology for immunotherapy of non-small cell lung cancer (NSCLC) patients.

Assessment of efficacy of anticancer vaccines based on DCs in patients with NSCLC was conducted under phase III clinical trials «Randomized, double-blind, parallel-group study of the effectiveness of dendritic cell autovaccine in combination with standard surgical treatment for patients with non-small cell lung cancer stage IIB-IIIA «. This study determined the efficacy of inclusion of cancer vaccine based on DCs in the treatment of NSCLC patients in the adjuvant setting mode and established the features of cell-mediated immune response in patients under the influence of anticancer immunotherapy.

The study found that the use of antitumor vaccines based on DCs in the treatment of NSCLC patients contributed significantly to increase their 5 -year overall and disease-free survival, lengthening the time to disease progression, and increase in a survival median [28]. In particular, the rate of the overall 5-year survival of NSCLC patients increased by $25 \%$ < $0.001 ; \mathrm{HR}=0.22$ (95\% Cl: 0.13-0.39).

At present, it is important to determine in clinical trials DCs characteristics that have therapeutic effectiveness. Accordingly, the purpose of the work was to investigate the phenotypic and functional properties of DCs of monocyte origin, as a basis in anticancer immunotherapy of patients with non-small cell lung cancer.

\section{MATERIALS AND METHODS}

Dendritic cells culture. DCs were generated from the monocytes of 10 healthy people aged 23 to 45 years $(34.9 \pm 5.4)$ and 40 patients with NSCLC IIB-IIIA stages aged 42 to 82 years $(53.9 \pm 3.4)$. Peripheral blood mononuclear cells were obtained using Histopaque-1077 (Sigma, USA) separation technique, after which the cells were resuspended in RPMI-1640 medium (Sigma, USA) supplemented with $2 \mu \mathrm{M} / \mathrm{L} \mathrm{L}-\mathrm{Gly}, 100 \mu \mathrm{g} / \mathrm{mL}$ streptomycin and 100 units/mL penicillin (Darnitsa, Ukraine) and incubated in a culture flask at $37^{\circ} \mathrm{C}, 5 \% \mathrm{CO}_{2}$ atmosphere for 2-3 hours. After non-adherent cells were removed by gentle washing, the concentration of adherent cells was adjusted to $0.5 \cdot 10 \%$ mL by culture medium, added with $1 \%$ autologous plasma and 100 $\mathrm{ng} / \mathrm{ml}$ of human GM-CSF Leucomax (Novartis, India), $20 \mathrm{ng} / \mathrm{mL} \mathrm{IL-4} \mathrm{(Sigma,}$ USA) and cultured for 8 days in $\mathrm{CO}_{2}$ incubator at $37^{\circ} \mathrm{C}$ and $5 \% \mathrm{CO}_{2}$. Growth factors were added to DCs again on the $3^{\text {rd }}$ day of cultivation. On the $6^{\text {th }}$ day of cultivation, as a source of tumor-associated antigens, we used autologous lyophilized tumor cells at a concentration of $0.05 \mathrm{mg} / \mathrm{ml}$ culture medium. On the $7^{\text {th }}$ day of maturation we added $100 \mathrm{ng} / \mathrm{mL}$ LPS (Sigma, USA) and 10,000 units/mL IFN-2ab «Laferobion» (Biopharma, Ukraine). All manipulations were carried out under aseptic conditions.

In NSCLC patients, autologous DCs-based immunotherapy was administered in an adjuvant mode, after primary treatment. Immunotherapy started 10-14 days after surgery. DCs were injected intravenously at a dose $3.0-10.0 \cdot 10^{6}$ cells per injection. All patients underwent 4 treatment stages at intervals of one per month. The written informed consent was obtained from all patients. The research was conducted according to ethical standards adopted by Ukrainian legislation. In NSCLC patients they were conducted under phase III of clinical trials approved by Central Ethics Committee of the Ministry of Health of Ukraine (No. 5.12-1201/KE, 05.11.2009).

Immunological methods. Analysis of DCs' phenotypic characteristics was performed by flow cytometry using FITC-conjugated monoclonal antibodies to CD83, CD86, and phycoerythrin-labelled antibodies to HLADR (Beckman Coulter, USA). Analysis of samples was performed with BD FACSCalibur flow cytometer (Becton Dickinson, USA) using CellQuestPRO software (Becton Dickinson, USA).

Quantitative real time polymerase chain reaction (qPCR) analysis. The total RNA was isolated from DCs using «Ribo-sol-A» (Amplisens, Russia) according to manufacturer's instructions. For the reverse transcription reaction, we used PCR test kit «Reverta-L-100» (Amplisens, Russia).

The level of mRNA expression of cytokine genes IL-12r35, IL-12r40, INF- $\gamma$, IL-10, TNF-a and chemokine CCR7 was determined by the 7500 Real-Time PCR Systems (Applied Biosystems, USA) using specific primers and probes (for IL-12r35, IL-12r40) or SYBR Green dye (Thermo Scientific, USA) for others. Sequences of primers and probes were selected using the Primer Express ${ }^{\circledR}$ Software v3.0 and synthesized by Applied Biosystems (USA). Reproducibility of amplification was tested in parallel experiments by repeating qPCR on samples of all RNA with each primer at least three times. After each amplification cycle, we detected fluorescence of the SYBR Green dye, and a melting curve was analyzed to control the formation of primer dimers and specificity of the reaction. The initial amount of mRNA was calculated by comparative CT method $(\triangle \triangle C T)$, the effectiveness of $P C R$ reactions was similar ( $E X=10^{-1 / 15 l o p e}$ -1 , slope $<0.1$ ) [20]. The of gene expression level of cytokines was evaluated using $\Delta \Delta$ Ct method with normalization according to expression of control gene glyceraldehyde-3-phosphate dehydrogenase (GAPDH).

Determination of cytokine IL-12p70 concentration in culture medium of differentiated DCs was performed using IL-12(p70) ELISA Kit Human (Thermo Scientific, USA).

Statistical methods. Statistical analysis was conducted using the Statistica 10.0 software (Stasoft Inc., USA). To compare the data in two groups we used Student's t-test and Mann-Whitney test. The difference was considered statistically significant at $p<0.05$. 

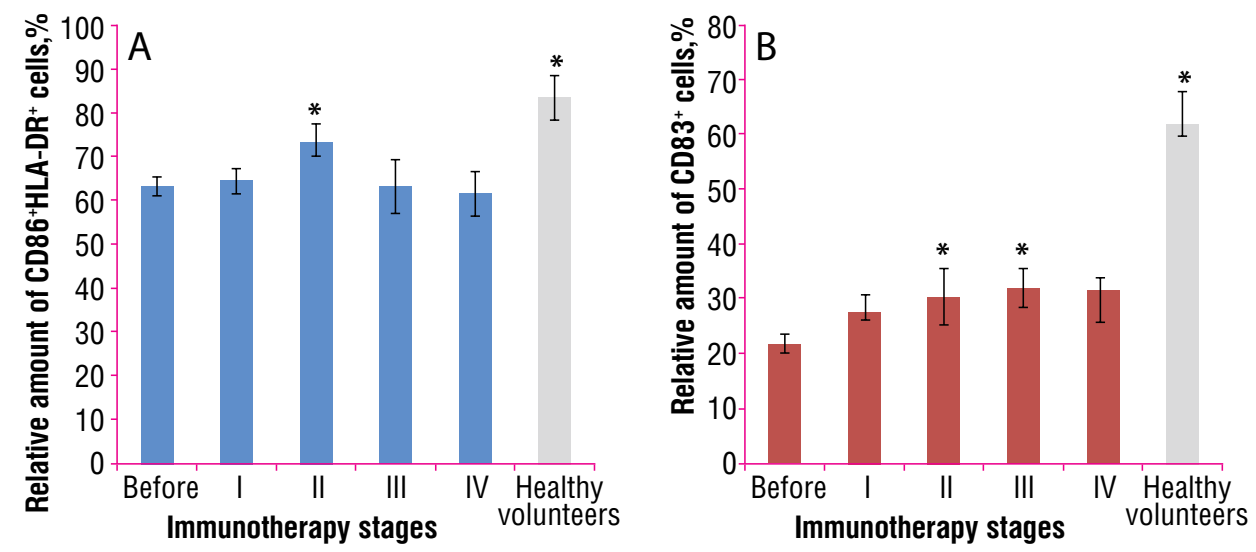

$<$ Fig. 1. Phenotypic characteristics of DCs of NSCLC patients at stages of immunotherapy $(n=34)$, HV - healthy volunteers $(n=10)$.

Note: ${ }^{*}-p<0.05$ compared with the values before the immunotherapy.

\section{RESULTS AND DISCUSSION}

DCs quality control included evaluation of phenotypic characteristics at the final stage of DCs vaccine production just before its administration. DCs phenotype indicate the readiness of cells to perform certain functions: interaction with T-cells, contact with tissue microenvironment and secretion of cytokines. The main DCs markers that characterize the degree of their maturity and functional capacity are surface molecules CD80, CD86, CD40, CD83 and HLA-DR, and others. [29-31]. DCs phenotype depends on the stage of maturation and activation.

Studies have shown that DC of the patients with NSCLC before immunotherapy were partially mature (Fig. 1). Thus, the level of simultaneous expression of CD86+ and $\mathrm{HLA}^{+} \mathrm{DR}^{+}$was $63.50 \pm 2.15 \%$, expression of CD83 was $21.44 \pm 1.70 \%$ versus $83.39 \pm 4.91 \%$ and $62.02 \pm 5.67 \%$ respectively in healthy people, $p<0.05$. The expression of CD83 marker that determines the DCs maturity increased slightly with each consecutive stage of immunotherapy, but did not reach the level of healthy volunteers. The expression of markers that characterize the antigen-presenting function of DCs at all stages of immunotherapy remained almost unchanged.

Modern requirements to assessment of DCs properties are not limited to phenotype; there is the need to identify functional activity, especially Th1-polarization. After cultivation ex vivo DCs must be viable, because they cannot meet antigen specific T-cells in the lymph nodes for long enough. DCs maturation improve their survival and thus has antiapoptotic effect. This happens mainly at enhancing of $\mathrm{Bcl}-\mathrm{xL}$ and $\mathrm{Bcl}-2$ expression [32]. In addition, DCs maturation protects them against NKcell lysis [33].

Measurement of anti-apoptotic Bcl-2 protein using flow cytometry revealed that its level in DCs in NSCLC patients is no different from the level in healthy volunteers, and almost unchanged at all stages of immunotherapy. Thus, the percentage of cells expressing Bcl-2 and intensity of expression (mean fluorescence intensity - MFI) in DCs of NSCLC patients amount to $97.51 \pm 0.73 \%$ and $1001.16 \pm 247.17 \mathrm{MFI}$ units vs $98.93 \pm 1.15 \%$ and $1123.36 \pm 215.16 \mathrm{MFI}$ units in healthy people respectively.

Realization of DCs function is largely determined by their localization in the tissue and the ability to migration. DCs migration is regulated by the interaction of chemokines with their receptors, various proteases and their respective receptors, such as urokinase plasminogen activator-system (UPA)/UPAR. The main chemokine receptor responsible for DCs migration is CCR7. Chemokines CCL19 (ELC) and CCR21 (SLC), recognized by the receptor CCR7, provide the migration to the T-cell zone of the lymph nodes. These chemokines are secreted by stromal cells in lymph nodes.

According to the results of our studies, activity of CCR7 gene in DCs from NSCLC patients is almost unaffected, the level of mRNA gene expression is even slightly higher than in healthy volunteers' DCs (Fig. 2).
After the four stage of immunotherapy, the difference in levels of mRNA expression of CCR7 in DCs of NSCLC patients and healthy people became statistically significant.

Along with the ability to induce activation of immunocompetent cells, DCs may suppress the immune response. Tolerogenic regulatory properties of DCs are due to different mechanisms, including the ability to express co-inhibitory molecules and receptors (B7-H1, ILT-2, ILT-3, ILT-4, CD209, CD200R and HLA-G), producing immunosuppressive cytokines (IL- 10, IDO, TGF- $\beta$ ) and induce generation of $C D 4^{+} \mathrm{CD} 25^{+} \mathrm{T}_{\text {reg }}$ [34-36].

Tolerogenic effects of DCs are accompanied by the initiation or increasing expression of certain molecules, which requires activation of genes. According to the results of studies, mRNA expression of immunosuppressive molecules in DCs of NSCLC patients is increased compared to DCs of healthy volunteers $-p<0.05$ for TGF- $\beta$ (Fig. 3).

By stage four of immunotherapy, the level of TGF- $\beta$ mRNA expression decreased to the level of DCs of healthy volunteers. The level of IDO mRNA expression also significantly reduced at stages III-IV immunotherapy, its level was significantly lower, compared to that in DCs before the beginning of immunotherapy and levels in DCs of healthy individuals.

The main cytokine that determines Th1-polarizing properties of DCs is IL-12. Bioactive IL-12p70 is a heterodimeric complex composed of two subunits $p 35$ and $p 40$. Our research showed that the expression of these cytokines in DCs of NSCLC patients (the beginning of immunotherapy) and in DCs of healthy people do not have significant differences (Fig. 4). Slightly lower level of mRNA IL-12p35 and immunosuppressive IL-10 was registered in DCs of healthy volunteers.

Fig. 2. The level of mRNA CCR7 expression in DCs of NSCLC patients with at stages of immunotherapy $(n=16), H V$ - healthy volunteers $(n=10)$.

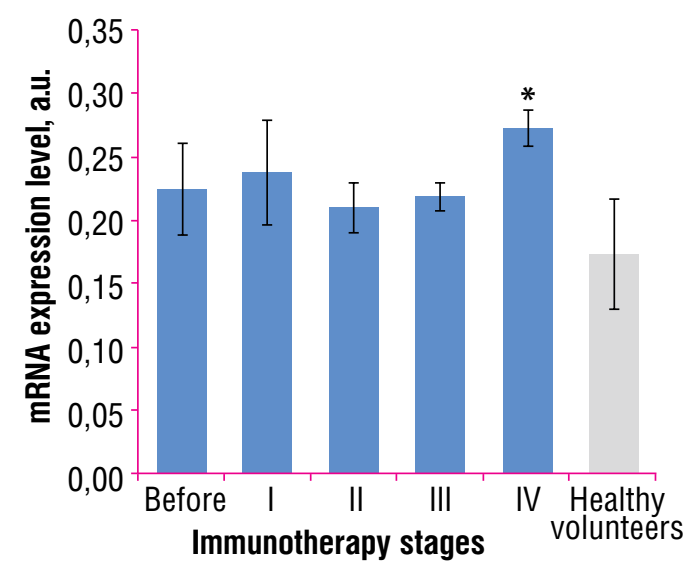

Note: * $-p<0.05$ compared with the values before the immunotherapy. 

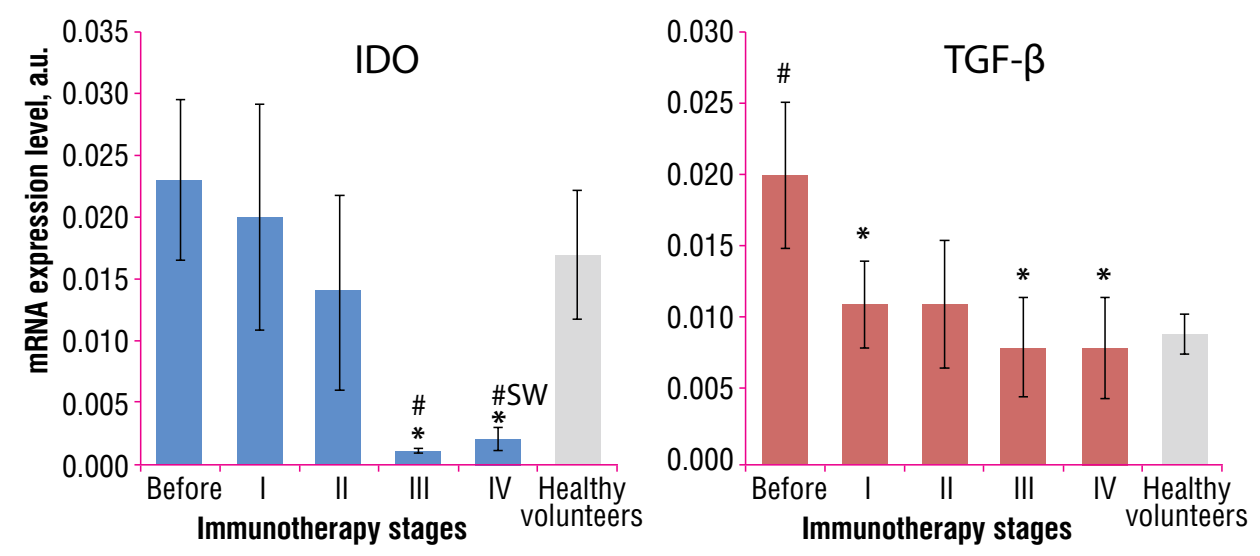

Fig. 3. The level of IDO and TGF- $\beta$ mRNA expression in DCs of NSCLC patients $(n=17)$ during immunotherapy. HV - healthy volunteers $(n=10)$.

Notes:

${ }^{*}-p<0.05$ compared to the values

before the beginning of immunotherapy; $\#-p<0.05$ compared to the value of healthy volunteers.

Fig. 4. The level of mRNA expression of cytokines in DCs of NSCLC patients $(n=17)$ and healthy volunteers $(n=10)$.

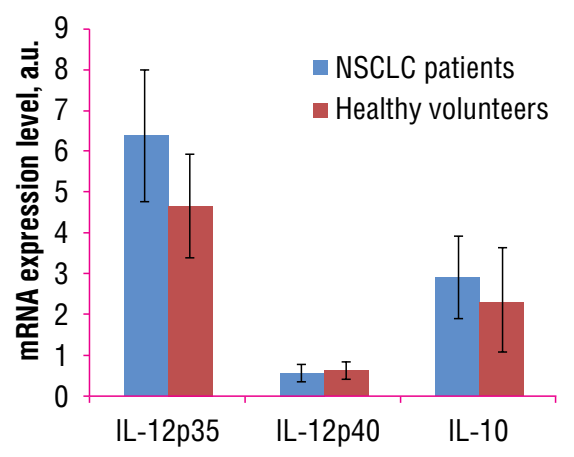

At the same time, study of bioactive IL-12 amount in DCs culture medium found violations of its synthesis in NSCLC patients. Thus, the amount of this cytokine in DCs culture medium of NSCLC patients was significantly lower than in healthy volunteers (Fig. 5). The data indicate the need for further optimization of technologies for obtaining DCs in NSCLC patients, with emphasis on the stimulation of Th1-polarizing properties by increasing cytokine secretory potential.
Fig. 5. The amount of IL-12p70 in DC culture medium of NSCLC patients $(n=17)$ and healthy volunteers $(n=10)$.

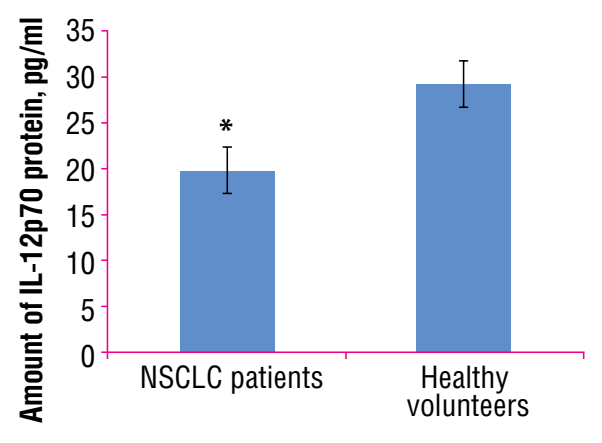

Note: * $-p<0.05$ compared to the value of healthy volunteers.

The use of the integrated approach to the creation of autologous cancer vaccines using modern high-tech methods, based on biological characteristics of DCs, will help improve and develop the most effective protocols of making and rational use of DCs vaccines. This will ensure greater confidence of both professionals and patients in anticancer vaccinotherapy and open new opportunities for the treatment of patients with cancer.

\section{CONCLUSIONS}

1. Dendritic cells populations in non-small cell lung cancer patients are characterized by increase of partially mature cells percent, indicating a violation of their differentiation.

2. The level of CD83 expression, which determines the degree of DCs maturity, increases during cancer immunotherapy.

3. CCR7 gene activity in DCs of NSCLC patients with is almost unaffected, which may indicate a preservation of their migratory properties.

4. The level of expression anti-apoptotic protein BCI-2 in DCs of NSCLC patients is different from the level in DCs of non-cancer people, and unchanged at the stages of immunotherapy.

5. The level of TGF- $\beta$ and IDO mRNA expression in DCS of NSCLC patients significantly increased in comparison with DCs of healthy volunteers. Their level significantly reduces during cancer immunotherapy.

6. In DCs of NSCLC patients, the synthesis of bioactive IL-12 is violated, indicating the need for further optimization of technologies for obtaining Th1-polarizing DCs in NSCLC patients.

\section{REFERENCES}

1. Shortman K, Caux C. Dendritic Cell Development: Multiple Pathways to Nature's. Adjuvants Stem Cells. 1997; 15:409-419. doi:10.1002/stem.150409

2. Dhodapkar MV, Steinman RM, Krasovsky J, et al. Antigen-specific inhibition of effector T cell function in humans after injection of immature dendritic cells. J Exp Med. 2001; 193(2):33-38. 
3. Figdor CG, de Vries IJ, Lesterhuis WJ, et al. Dendritic cell immunotherapy: mapping the way. Nat Med. 2004; 10(5):475-80.

4. Kawakami Y, Fujita T, Kudo C, et al. Dendritic cell based personalized immunotherapy based on cancer antigen research. Front Biosci. 2008; 13:1952-58.

5. Palucka K, Banchereau J. Cancer immunotherapy via dendritic cells. Nat Rev Cancer. 2012; 12(4):265-77. doi:10.1038/nrc3258

6. Hettihewa $L M$. Prolonged expression of MHC class I - peptide expression in bone marrow derived retrovirus transfected matured dendritic cells by continuous centrifugation in the presence of IL-4. Indian J Med Res. 2011; 134(5):672-78.

7. Dieckmann D, Schultz E, Ring B, et al. Optimizing the exogenous antigen loading of monocyte-derived dendritic cells. Int Immunol. 2005; 17:621-35.

8. Dudek AM, Martin S, Garg AD, et al. Immature, Semi-Mature, and Fully Mature Dendritic Cells: Toward a DC-Cancer Cells Interface That Augments Anticancer Immunity. Front Immunol. 2013; 4:438-52.

9. Trepiakas $R$, Pedersenc AE, Svanea IM. Addition of interferon-alpha to a standard maturation cocktail induces CD38 up-regulation and increases dendritic cell function. Vaccine. 2009; 27:2213-19.

10. Raich-Regue D, Naranjo-Gomez M, Grau-Lopez L, et al. Differential effect of monophosphoryl lipid A and cytokine cocktail as maturation stimuli of immunogenic and tolerogenic dendritic cells for immunotherapy. Vaccine. 2012; 30:378-87.

11. Richter C, Thieme S, Bandoła J, et al. Generation of Inducible Immortalized Dendritic Cells with Proper Immune Function In Vitro and In Vivo. PLoS One. 2013; 8(4):62621.

12. Sabado R, Bhardwaj N. Cancer immunotherapy: dendritic-cell vaccines on the move. Nature. 2015; 19(519):300-301. doi:10.1038/nature14211

13. Anguille S, BryantEC, et al. Dendritic Cells as Pharmacological Tools for Cancer Immunotherapy. Pharmacol Rev. 2015; 67(4):731-753. doi:10.1124/pr.114.009456.7

14. Park J, Gerber MH, Babensee JE. Phenotype and polarization of autologous t cells by biomaterial-treated dendritic cells. J Biomed Mater Res A. 2015; 103(1):17084. doi:10.1002/jbm.a.35150

15. Khranovskaia NN, Grinevich IuA, Potebnia GP, Vorod'eva LI, et al. Vliyanie dendritnokletochnoy autovaktsiny na effektivnost' lecheniya bol'nykh rakom yaichnika [Effect of dendritic cell autovaccine on the treatment outcome in patients with ovarian cancer]. Vopr Onkol. 2012; 58(6):781-86. [in Russian]

16. Amigorena S, Savina A. Intracellular mechanisms of antigen cross presentation in dendritic cells. Curr Opin Immunol. 2010; 22(1):109-17.

17. Baldueva IA, Novik AV, Moiseenko VM. Klinicheskoe issledovanie (II faza) vaktsiny na osnove autologichnykh dendritnykh kletok $\mathrm{s}$ immunologicheskim ad»yuvantom u bol'nykh s melanomoy kozhi. [Clinical Study (II phase) of vaccine based on autologous dendritic cells with immunological adjuvants in patients with melanoma]. Vopr Onkologii. 2012; 58(2):212-221. [in Russian]

18. Butterfield LH. Dendritic Cells in Cancer Immunotherapy Clinical Trials: Are We Making Progress? Front Immunol. 2013; 4:454-82.

19. Vacchelli E, Vitale I, Eggermont A. Dendritic cell-based interventions for cancer therapy. Oncolmmunology. 2013; 2(10):25771

20. Kantoff PW, Higano CS, Shore ND, et al. Sipuleucel-T immunotherapy for castration-resistant prostate cancer. N Engl J Med. 2010; 363:411-22.

21. Johnson LA, Jackson DG. Cell Traffic and the Lymphatic Endothelium. Ann N Y Acad Sci. 2008; 1131:119-33.

22. Gollmann $\mathrm{G}$, Neuwirt $\mathrm{H}$, Tripp $\mathrm{CH}$, et al. Sphingosine-1-phosphate receptor type-1 agonism impairs blood dendritic cell chemotaxis and skin dendritic cell migration to lymph nodes under inflammatory conditions. Int Immunol. 2008; 18(1):49-54.

23. Fucikova J, Kralikova P, Fialova A, et al. Human tumor cells killed by anthracyclines induce a tumor-specific immune response. Cancer Res. 2011; 71(14):4821-33. doi: 10.1158/0008-5472.CAN-11-0950

24. Navabi $H$, Jasani B, Reece A, et al. A clinical grade poly I:C-analogue (Ampligen) promotes optimal DC maturation and Th1-type T cell responses of healthy donors and cancer patients in vitro. Vaccine. 2009; 27(1):107-15. doi: 10.1016/j.vaccine.2008.10.024

25. Kalinskia $P, O$ Kada H. Polarized dendritic cells as cancer vaccines: Directing effector-type T cells to tumors. Seminars in Immunology. 2010; 22:173-82.

26. Mailliard RB, Wankowicz-Kalinska A, Cai Q, et al. a-Type-1 Polarized Dendritic Cells: A Novel Immunization Tool with Optimized CTL-inducing Activity. Cancer Resaerch. 2004; 64:5934-37.

27. Khranovskaia NN, Skachkova OV, Svergun NN. Fenotipicheskaya i funktsional'naya kharakteristika generirovannykh in vitro dendritnykh kletok cheloveka posle aktivatsii lipopolisakharidom i interferonom-a [Phenotypic and functional characterization of dendritic cells generated in vitro after activation by human lipopolysaccharide and interferon-a]. Imunologiya ta alergologiya - Immunology and allergology. 2013; 4:72-76. [in Russian]

28. Khranovskaia NN, Kryachok IA, Ganul VL, et al. Razrabotka, obosnovanie i otsenka effektivnosti protivoopukholevoy vaktsinoterapii na osnove dendritnykh kletok u bol'nykh so zlokachestvennymi novoobrazovaniyami [Elaboration, rationale and clinical benefit of antitumor vaccine therapy based on dendritic cells for patients with malignant neoplasms]. Klinichna onkologiya - Clinical Oncology. 2014; 2(14):62-70. [in Russian]

29. Chernykh EP, Leplina OYu, Tyrinova TV, et al. Protivoopukholevaya aktivnost' dendritnykh kletok zdorovykh donorov i bol'nykh s opukholyami golovnogo mozga [The antitumor activity of dendritic cells from healthy donors and patients with brain tumors]. Med immunologiya - Med Immunology. 2010; 12(3):199-206.

30. Chiang CL, Maier DA, Kandalaft LE, et al. Optimizing parameters for clinical-scale production of high IL-12 secreting dendritic cells pulsed with oxidized whole tumor cell lysate. J Transl Med. 2011; 9:198-230.

31. Draube A, Klein-Gonzalez N, Mattheus S, et al. Dendritic Cell Based Tumor Vaccination in Prostate and Renal Cell Cancer: A Systematic Review and Meta-Analysis. PLoS One. 2011; 6(4):18801. doi:10.1371/journal.pone.0018801

32. Pletinckx K, Stijlemans B, Pavlovic V, et al. Similar inflammatory DC maturation signatures induced by TNF or Trypanosoma brucei antigens instruct default Th2cell responses. Eur J Immunol. 2011; 41:3479-94. doi:10.1002/eji.201141631

33. Motta JM, Rumjanek VM. Sensitivity of Dendritic Cells to Microenvironment Signals. J Immunol Res. 2016. Retrieved from http://dx.doi.org/10.1155/2016/4753607

34. Raker VK, Domogalla MP, Steinbrink K. Tolerogenic Dendritic Cells for Regulatory T Cell Induction in Man. Front Immunol. 2015; 6:569. doi:10.3389/ fimmu.2015.00569

35. Manicassamy S, Pulendran B. Dendritic cell control of tolerogenic responses. Immunol Rev. 2011; 241(1):206-27. doi:10.1111/j.1600-065X.2011.01015.X

36. Gordon JR, Ma Y, Churchman L, et al. Regulatory Dendritic Cells for Immunotherapy in Immunologic Diseases. Front Immunol. 2014; 5:1-19. doi:10.3389/ fimmu.2014.00007

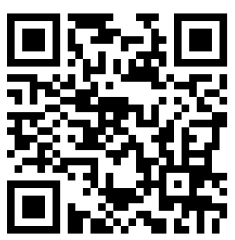

The authors indicate no potential conflicts of interest.

ARTICLE ON THE SITE TRANSPLANTOLOGY.ORG
Received: October 30, 2016

Accepted: November 29, 2016 